Meta

Journal des traducteurs

Translators' Journal

\title{
Sign Language Interpreting in Germany on the Way Towards Professionalism
}

\section{Andrea Schulz}

Volume 42, numéro 3, septembre 1997

L’interprétation en langues des signes

URI : https://id.erudit.org/iderudit/004054ar

DOI : https://doi.org/10.7202/004054ar

Aller au sommaire du numéro

Éditeur(s)

Les Presses de l'Université de Montréal

ISSN

0026-0452 (imprimé)

1492-1421 (numérique)

Découvrir la revue

Citer cet article

Schulz, A. (1997). Sign Language Interpreting in Germany on the Way Towards Professionalism. Meta, 42(3), 546-549. https://doi.org/10.7202/004054ar

\section{Résumé de l'article}

Afin de répondre à la nécessité de former des interprètes en langue des signes, l'Université de Hambourg a implanté, en 1993-1994, en collaboration avec des linguistes, des interprètes et des professeurs du Centre for German Sign Language and Communication of the Deaf, un programme menant à un diplôme universitaire. Cet article rend compte de ce programme et en décrit la structure et les composantes. 


\title{
SIGN LANGUAGE INTERPRETING IN GERMANY ON THE WAY TOWARDS PROFESSIONALISM
}

\author{
ANDREA SCHULZ \\ Centre for German Sign Language and Communication of the Deaf. \\ and University of Hamburg, Hamburg, Germany
}

\begin{abstract}
Résumé
Afin de répondre à la nécessité de former des interprètes en langue des signes, l'Université de Hambourg a implanté, en 1993-1994, en collaboration avec des linguistes, des interprètes et des professeurs du Centre for German Sign Language and Communication of the Deaf, un programme menant à un diplome universitaire. Cet article rend compte de ce programme et en décrit la structure et les composantes.
\end{abstract}

\begin{abstract}
Responding to the need to provide formal training and certification for sign language interpreters, in 1993-94 the University of Hamburg in a collaborative effort by linguists, interpreters and deaf lecturers of sign language, implemented a program leading to the "Diploma in Sign Language Interpreting." This article describes the structure and components of the program of studies.
\end{abstract}

Anyone who - due to professional reasons or personal interest - takes a closer look at the development of the occupation of "Sign Language Interpreter" will find that it is tightly interwoven with the varying history of the deaf community in Germany.

The earliest known source in the German language which mentions a "transmission for the deaf-mute" dates back to 1785 . Between this early testimony and today, quite a few references to this kind of activity and/or to the people pursuing it can be found. Such reports have been everything else but systematically collected in archives, nor were they always produced on the basis of professional interest - in most instances remarks on the context discussed here can be found in marginal notes only -, but nevertheless they very clearly reveal that the reputation of these people and of their activity is always bound up with the standing of sign language and of the language user group, i.e. the deaf community. In times which could be characterized as "the blossom of deaf culture" (when deaf people were known, recognized, and represented in any occupational group, including academic professions), we find far more and clearly more positive descriptions of sign language interpreting than in the very dark times of this language community. Under the rule of the Nazis in Germany, e.g., deaf people were among those affected by the attempts to systematically decimate and eradicate anything of different nature by compulsory sterilization and other forceful methods. In these times there obviously was no room for individuality, which would have been expressed by an independent language and culture. Even less needed were persons who might have acted as communicators between the cultures of the deaf and of hearing people. Despite numerous attempts to rob the deaf of their own cultural identity, this community has continued to exist until the present moment, and undeterred by many interventions of so-called benefactors and carers, the deaf community has managed to preserve and steadily develop its own language and culture. Consequently, the activity of transmitting spoken language into sign language and vice versa has been

Meta, XLII, 3, 1997 
preserved as well. It is quite intentional that I call this the activity of transmitting rather than the occupation or the professional practice of sign language interpreting. The concepts of "occupation" and "professionalism" imply a consensus about skills and competence as well as the provision of places (of thought, experience, and work) for the acquisition of these capabilities.

In defiance of all insights and suppositions, however, the interpreters of sign language have so far been denied the status of an independent occupational profile. An interpreter is nowadays defined as somebody whose occupational practice consists of translating utterances from one language and culture to another and thus establishing communication between two or more persons. But the interpreters of sign language were lacking appropriate opportunities. For more than 200 years they have been unable to obtain an occupational qualification, i.e. to complete a course of studies for sign language interpreters which would even have come close to other qualification programmes.

Partly due to ignorance, partly against better judgement, the field of so-called "sign language interpreting" offered rich opportunities for paternalistic attitudes towards the language community and for enhancing the image of the "interpreters", etc. Selfish interests were often pursued behind a "mask of benevolence," while the clients were unable to notice what was going on and/or had no chance of preventively eliminating certain people. Thus there were (and still are) many cases, in which the own helper syndrome or an "image neurosis" was satisfied instead of pursuing an activity within the defined scope. This negative picture also included some rather questionable practices on the part of some individual "interpreters" who were distinguished by crass profiteering rather than excelling by high-quality work.

At the same time there were always other people who, in the absence of an opportunity for obtaining a qualification somewhere, just gave their best and tried to perform their task as well as possible, especially as the demand for interpreting services appeared to be growing larger and more urgent. The pressure on this particular group of people kept increasing. They were getting caught up in the most difficult contexts without having an exact definition of tasks and responsibilities, and they were even held personally responsible for positive or negative outcomes. This was a burden which many of them could or would no longer bear. Highly motivated people with an excellent background who appeared to be predisposed to the profession of sign language interpreter moved away from it.

The language community of the deaf suffered from this development. In their struggle for the recognition of their language and culture, deaf people were, on the one hand, dependent on bilingual, bicultural people who could establish communication between their deaf community and the hearing community by way of translation. On the other hand, it was recognized time and again that this very bilingual and bicultural knowledge granted incredible power to the owners of such skills. This led the deaf to try and take some controlling measures. Their regional representations issued interpreter ID cards which were granted to those candidates who had taken an "examination" and whose performance had been considered adequate. Such examinations have been implemented in the German federal states of Hamburg (at the end of a "makeshift training course") since 1983, in Bavaria since 1983, in North-Rhine Westphalia since 1987, and in Schleswig-Holstein since 1991.

From today's perspective, these arrangements may appear to be provisional, especially since there was no training concept and hardly anything like a consensus on skills testing criteria. However, these efforts in the early 1980's generated an impulse: For the first time in more than 200 years, interpreting from and into sign language began to be considered as an activity which is not carried out on the basis of vague talents, but requires factual 
and technical qualifications. This triggered a heated debate on the definition of tasks and responsibilities of sign language interpreters, which were and still are extremely different in the various regions of the country. But everybody agrees that there is a steadily growing demand for sign language interpreter services, and that a training course is both necessary and indispensable.

Since the early 1990's an attempt has therefore been made at the University of Hamburg to respond to the aforementioned problems and deficits in an open-minded, competent and creative manner. Within the scope of a model experiment, the first - and so far the only - course of university studies for a "Diploma in Sign Language Interpreting" has been developed since the Winter Semester 1993/94 in a cooperative effort by linguists, interpreters and deaf lecturers of sign language at the Centre for German Sign Language and Communication of the Deaf. After the successful completion of the model experiment in July 1996, the course was firmly established as of the Winter Semester 1996/97. In the future, twenty study places for first-year university students will be made available in each winter semester.

In the following, I should like to give a brief outline of the structure and concepts of the course of studies for a diploma in sign language interpreting.

The standards of admission to the University of Hamburg have to be met as an entrance requirement. The course ends with a diploma examination for the academic degree "Diploma in Sign Language Interpreting." The successful completion of compulsory seminars and periods of work experience is required for admission to the diploma examination, which then consists of a diploma thesis as well as a theoretical and practical final examination. The focus of this course is on learning interpreting techniques in theory and practice on the basis of comprehensive linguistic competence in the German language, German Sign Language, and visual-tactile communication systems (manual alphabet, signed and sign-supported German, lip-reading, oral interpreting, tactile interpreting for deaf-blind people, and others). Moreover, skills are taught for interpreting in specific life situations and service environments of the deaf (authorities, health care, etc.), in education and training, including vocational training and continuing education, as well as social, cultural and political life.

The course in Sign Language Interpreting consists of eight major sections:

Language Competence: This area is designed to provide the basic practical language requirements for later work as an interpreter in the German language, German Sign Language, and visual-tactile communication systems. Students need to acquire a high level of language competence, and become familiar with the culture and social structure of the sign language community. In a contrastive relationship to German Sign Language, German Spoken Language has been included as a second language of reference.

Theory of Interpreting: Studying the rules of professional conduct and practice related to interpreting is an important part of this section. The historical development of "Sign Language Interpreting" as a profession is studied in national and international contexts. Attention is focussed on individual elements of the process of interpretation against the background of the state of the art in translation studies.

Interpreting Techniques: This section includes memory training as well as an introduction to the theory and practice of consecutive interpreting and note-taking techniques. It serves as preparation for the consecutive interpretation of face-to-face conversations, lectures and group discussions. This is followed by an introduction to simultaneous interpreting. Additional aspects are written translations, the sight translation of printed texts, telephone interpreting as well as team-specific interpreting activities such as shadow and relay interpreting. 
Rhetoric: Starting from the linguistic basics of text production, knowledge is provided about specific techniques related to the various practices of spoken and sign language in German-speaking countries as well as the visual-tactile communication systems used in this geographical area. Specific forms of expression within various age and social groups as well as among dialect users will also be considered.

Sociology and History of the Sign Language Community: Focuses on the social situation of the sign language community as a sign language minority, with due consideration of the history and development of the international deaf community.

Linguistics: Deals with the linguistic analysis and description of German Sign Language and German Spoken Language. The translation and scientific notation and transcription of sign language, including the introduction to relevant computer software programmes, constitute an essential part of the capabilities in linguistics.

Subject Areas: Technical introductions to various subject areas and scientific disciplines (medicine, psychology, law, computer science, education, linguistics, sports, theology, tourism, and theater) are compulsory for all students. This is intended as an important content-oriented foundation for proper interpretation in these areas. It includes in particular the teaching of crucial subject-related terminologies and the required vocabularies of signs for technical terms.

Administrative Procedures: This section seeks to provide basic information on administrative procedures. It deals not only with the administrative contexts of specific government authorities, but also with business management issues which are related to tax regulations, insurance, contracting, and the like. This knowledge is intended not only as a prerequisite for interpreting assignments in these fields, but also as practical assistance to interpreters who usually work on a freelance basis.

Although the course of studies is no longer in a model stage, the deaf and hearing members of the faculty still consider it as work in progress in many ways. They have a strong interest in an exchange of experience with representatives from other countries inside and outside of Europe. In the future, it is hoped that this course will stimulate interest and encourage contact between students in various countries. Last but not least, the practical orientation of this course demands that the study performance should steadily be measured against the requirements of day-to-day work. This calls for a continuous effort to try and close the gap between scientific theory and the real needs of society. 